\title{
Climate change in the Western Himalayas of India: a study of local perception and response
}

\author{
Neeraj Vedwan*, Robert E. Rhoades \\ The University of Georgia, Franklin College of Arts and Sciences, Department of Anthropology, 250A Baldwin Hall, \\ Jackson St., Athens, Georgia 30602-1619, USA
}

\begin{abstract}
This study examines how apple farmers in the western Himalayas of India perceive climatic change. This is done by comparing the locally idealized traditional weather cycle with climate change as perceived by the farmers of the region. We use snowfall and rainfall data from 1962-1996 to measure the accuracy of perceptions. Although climate change is usually described by farmers as the temporal displacement of the weather cycle, the changes themselves still are not perceived as altering the idealized weather calendar. Most importantly, perception of climate change is structured by knowledge of crop-climate interaction and by differential apple performance outcomes associated with the changed conditions.
\end{abstract}

KEY WORDS: Perceptions · Farmer decision-making · Traditional weather calendars · Apple · Himalayas

Resale or republication not permitted without written consent of the publisher

\section{INTRODUCTION}

The impact of global climatic change on agriculture has recently become a subject of increasing importance (Glantz 1988). Most studies, however, confine their inquiries to the biological and physical domains, concentrating mainly on representing the responses of crops to various changes in climate. Studies focusing on the socioeconomic aspects of global climatic change are sparse and have almost exclusively restricted their analyses to the impact of environmental modifications on agricultural production (e.g. Parry 1978, Lamb 1985, Post 1985, Parry et al. 1989, Scott et al. 1990, Chmielewski 1992). Most of these impact studies are dependent on the broad-scale predictive ability of general circulation models on which they are based, reducing the utility of these models in fine-scale studies at the regional or local level. The impetus for the broad-scale studies has been the interest in inventing broad policy recommendations, and both biological and economic researchers have taken a top-down approach to climate changes, focusing predominantly

*E-mail: nvedwan@hotmail.com on the macro agro-ecological level. Micro-level studies of the impact of climatic variability on people's livelihoods at the farm level and their consequent responses are relatively few, although Glantz (1994) has had some success in linking macro change with micro effects by researching institutional mechanisms that respond to environmental perturbations. In light of the uncertainties involved in diachronically modeling climatic events, as well as the general paucity of longterm climatic data in developing countries, it has been suggested that research on cultural adaptations and climate would yield useful insights (Crumley \& Marquarat 1987, Gunn 1994, Orlove et. al. 2000). To this end, individual farmers' understandings and perceptions of climate assume critical importance. Our study is based on the premise that any research aimed at understanding (1) the impact of climate change and variability and (2) the resulting socioeconomic responses, should take into account farmers' awareness of weather fluctuations. It is our hypothesis that understanding local perceptions of the relative amounts, direction, and impact of climate change are key to arriving at an understanding of patterns in human responses. 


\section{CASE STUDY}

The Kullu Valley in the western Himalayas of India comprises the apple belt in the state of Himachal Pradesh and is famous throughout India for its apples. Over the past decade, however, the valley has witnessed a steady decline in apple production, owing mainly to a fall in productivity. In 1995, apple production amounted to just one-fourth that of the peak production year of 1988-1989 (Apple Growers Association 1997). The 2 main commercial varieties of apple in the valley are Red Delicious and Royal Delicious. Both are highly valued for their color and size attributes. Colloquially they are called 'female' apples. The valley has witnessed a continuous decline in apple quality in these 'female' varieties for more than a decade. 'Male' varieties used for cross-pollination ('pollinators'), including Golden Delicious, have suffered less from the climatic uncertainty but are not commercially important. The present-day low productivity crisis first appeared in the year 1989-1990, when the valley production hit an all time low - a 50\% reduction from the previous all-time-high year. Production, while experiencing some seasonal fluctuations, has not recuperated fully and an overall decline continues.

In this paper we will examine local perceptions of the climate variables seen as responsible for this decline in apple quantity and quality. The specific questions this paper seeks to answer are: (1) Along what dimensions do people perceive climate change? What are the climatic attributes that are seen as having undergone a change? (2) How do people discern 'climate' and 'climate change', especially as climate comprises a continuous impingement of potential information on senses? In other words, through what categories are climate/climatic change perceived? Are they limited to the traditional categories of their local weather calendar? (3) Can climate change be recognized or can people only perceive weather (Kempton et al. 1995)? Are susceptible farmers more attuned than others to perturbations in the environment?

To consider why local perceptions, such as those of Himalayan apple farmers in this study, are more accurate for certain kinds of weather and climate change, it is useful to look at mechanisms by which weather affects agricultural output. Parry's (1978) summary of these mechanisms includes changes in: (1) length of the potential growing season, (2) plant growth rates, (3) mean yield, (4) variability of yields, (5) level of crop certainty, or the probability of a given yield, (6) yieldquality, possibly unrelated to change in the yield or amount, and (7) sensitivity of plants to agricultural inputs. With Parry's potential effects as a backdrop, we chose apple as an 'indicator' ${ }^{1}$ or 'proxy' crop for several reasons. First, apple is relatively strongly coupled to the environment, especially by variations in climatic parameters. For instance, timing and amount of snowfall and frost in early spring have significant influence on the quality and quantity of apples produced. Second, apple constitutes the mainstay of the regional economy. Moreover, the importance of the apple reaches far beyond its significance in the livelihoods of the people. The cultural significance of apple can be adequately understood only by considering the historical and political-economic factors of agricultural production in Himachal Pradesh. These biological and socio-cultural dimensions of apple production, along with readily available production and climatic data, make it an ideal subject for the analysis of decisionmaking and climate change. Finally, since the area of study is mountainous, it is possible to discern the shift in the apple belt in terms of the response of the upper and lower limits of cultivation to the change in temperature profile.

\section{HISTORY OF APPLE PRODUCTION IN HIMACHAL PRADESH}

The study area comprises the Kullu Valley in the Himachal Pradesh Himalayan State, Northwestern India. The area lies between $31^{\circ} 21^{\prime} \mathrm{N}$ and $32^{\circ} 59^{\prime} \mathrm{N}$ and $76^{\circ} 49^{\prime} \mathrm{E}$ and $78^{\circ} 59^{\prime} \mathrm{E}$, comprising a total of $5503 \mathrm{~km}^{2}$. The elevation ranges from 350 to $6500 \mathrm{~m}$ above sea level. Himachal Pradesh was administratively reorganized in 1966 (Sharma 1997), at which point Kullu Valley became integrated into the territory. Himachal Pradesh, in focussing on its upland areas such as the Kullu Valley, embarked on an expansion program for horticultural crops after the attainment of full statehood in 1971. The area under fruit crop cultivation increased from 6004 ha in 1960-1961 to 1095684 ha in 1995-1996 (Directorate of Horticulture 1998). Prior to this, agriculture in the Kullu Valley was predominantly of the subsistence type based on staples such as rice, wheat and corn. Moreover, the green revolution had still not impacted the region due to the prevailing agricultural systems in the hilly terrain. Most cereal production came from the local, hard landraces while hybrids were virtually unknown. Some of these landraces are still extant, although the area under cultivation of these subsistence crops is rapidly shrinking (Sharma 1997). Not surprisingly, most subsistence crops are cultivated by small-scale farmers at the upper agro-ecological margins of the valley.

\footnotetext{
${ }^{1}$ The term 'indicator species' is used for apple in the Kullu Valley not solely due to its phenological properties but because of its cultural significance, a function of agricultural history and political ecology of the region
} 
Table 1. Horticultural land uses in Kullu Valley, Himachal Pradesh, India in 1989-1990

\begin{tabular}{|lr|}
\hline Area under horticulture & 19340 ha \\
Area under apple & 14244 ha \\
Fruit trees & 4379889 \\
Apple trees & 3665662 \\
Total orchardists & 34448 \\
Source: Directorate of Horticulture, Shimla & \\
\hline
\end{tabular}

Table 2. Land distribution in Kullu Valley, Himachal Pradesh, India, in 1989-1990. Land holdings are fragmented but the stringent conditions required for successful apple cultivation restrict potential suitable sites. Orchardists, therefore, usually have 1 parcel of prime apple orchard in the 'belt', whereas the remaining parcels are used for other crops and are considered marginal for apple cultivation even when they have been planted with apple trees, usually in the earlier boom periods

$\begin{array}{lr}\text { Less than } 2.5 \text { ha } & 30136 \text { families } \\ 1-2 \text { ha } & 3192 \text { families } \\ 2-4 \text { ha } & 951 \text { families } \\ 4-10 \text { ha } & 152 \text { families } \\ \text { More than } 10 \text { ha } & 17 \text { families } \\ \text { Source: Directorate of Horticulture, Shimla } & \end{array}$

Given the area's dependence on apple, and the lack of other options, climatic conditions have become more critical for people's livelihood strategies in the Kullu Valley with time. Table 1 reflects in very significant ways the changes that have taken place in the region's agriculture over the past 2 decades. Primarily, the emphasis has shifted from subsistence to commercial farming. For example, the area under cereal crop cultivation has undergone a drastic reduction, especially for landrace varieties. The area thus freed has been converted to orchards. Over the last 2 decades (1977-1997), the area under orchard has undergone an increase from $28 \%$ to about $60 \%$ (Apple Growers Association 1997). Moreover, most of the orchards planted after 1975 have been predominantly on land belonging to small-scale and marginal farmers. Although this shift initially served well the interests of small- and medium-scale farmers, it also has engendered dependence on the market for the household subsistence needs. The system changes in production have penetrated all spheres of life, from the food people consume to the way people dress and relate to each other.

Orchardists have suffered a great deal in socioeconomic terms in the last decade on account of a declining apple economy. With the rise in income from apple and other fruit crops, the education of orchard family children had assumed a new priority. However, with education came a general reluctance of young people to work in the fields and orchards, preferring instead to take more prestigious urban-oriented occupation. Moreover, when apple production declined, it was not possible for farmers of apple and similar crops to easily shift over to other crops, because of the massive startup investment for trees nurtured over an $8 \mathrm{yr}$ period before beginning to bear fruit. The smallholder class of apple farmers ( 2 to 5 acres; 0.8 to 2 ha) who had stopped cultivating for subsistence was the worst hit, and crop failure for even $1 \mathrm{yr}$ left them with no course other than to look to bank loans for bailouts. Tables 1 \& 2 summarize land distribution and use for the Kullu Valley.

An alternative to farming in the region is public works employment, which typically is not sought by the middle class. Larger farmers moderately diversified into the tourism industry (e.g. hotels, guest houses, taxis) as it began to take off $10 \mathrm{yr}$ ago. This option was less accessible to the capital-poor middle class, who sought to make up for the lack of capital and know how with bank loans. Little did local people realize that the volume of tourism was soon to prove woefully short of their expectations, resulting in the success by only a few larger hotels.

From interviews of 5 key government agricultural scientists engaged in research and extension in the area, we discovered that they recognized the climate as changing, or at least an increased variability of weather. Regarding the decline of apple production, they emphasized technical solutions. For instance, it was iterated time and again that one of the driving forces behind the present crisis was the lack of pollinizers. The official recommendation is that pollinizers should cover about $20 \%$ of any orchard. Scientists said that most of the trees which serve as pollinizers, such as Golden Delicious, had been chopped down and replaced with commercially lucrative varieties like Red Golden. However, the typical farmer responded to us in interviews that the number of pollinizers had decreased prior to the decline in apple performance. Scientists and local farmers were clearly not looking at the problem equivalently.

\section{THE HIMALAYAN WEATHER CALENDAR AND THE ASSOCIATED CYCLE OF AGRICULTURAL ACTIVITIES}

The traditional calendar of local Kullu Valley farmers represents ideal types or pristine, undisturbed climates. Different periods in the calendar year are usually described in conjunction with corresponding weather activities. The ideal cycle shown in Table 3 was created from interviews with older informants. They describe the traditional calendar as a relatively 
Table 3. Traditional calendar of the Kullu Valley

\begin{tabular}{|llll|}
\hline Local term & Approximate period & \multicolumn{1}{c|}{ Description (ideal) } & \multicolumn{1}{c}{ Description (present) } \\
\hline Magh & Jan 15-Feb 15 & Cold with snow fall & Some rain and snow \\
Falgun & Feb 15-Mar 15 & Less cold with snow & Rain \\
Chaitra & Mar 15-Apr 15 & Rain, snow rare & Some rain and snow \\
Baisakh & Apr 15-May 15 & No rain, clear skies (paddy, dal and corn sown) & Dry with some rain \\
Jeth & May 15-Jun 15 & Hot (paddy, dal and corn sown) & Dry \\
Asadh & Jun 15-Jul 15 & Hot (until June 30), pre-monsoon rain & Hot and dry \\
Sawan & Jul 15-Aug 15 & Rain & Hot and rainy \\
Bhadra & Aug 15-Sep 15 & Rain (until Aug 30, apple harvest), dry & Predominantly rainy season \\
& & & (stock of drying grass for fodder) \\
Ashwin & Sep 15-Oct 15 & Clear (corn, dal harvest; wheat, barley sown) & First half rainy and second half dry \\
Kartik & Oct 15-Nov 15 & Mostly clear (paddy harvest), shorter days & Same as ideal \\
Mangsir & Nov 15-Dec 15 & Snowfall, drying fir leaves and wood for fuel & Same as ideal \\
Paush & Dec 15-Jan 15 & Maximum cold with snow & Very little snow \\
Source: Field interview & & \\
\hline
\end{tabular}

accurate portrayal of local Kullu Valley weather until approximately 1970; they considered significant climate change to have occurred in subsequent decades.

\section{PERCEPTION OF CLIMATE CHANGE}

\subsection{Snowfall}

People perceived a definite reduction in snowfall over time. More specifically, snowfall events were thought to oscillate in 2 important ways: (1) reductions in the intensity of snowfall and (2) changes in the timing of snowfall. Recollection of memorable events, such as the largest snowfall in a decade, was the most common method individuals used to discuss reductions in the intensity of snowfall. There was a wide divergence in opinion concerning the timing of the onset of reductions in snowfall; for example, elderly informants believed the reduction in the amount of snow to have begun in the late $1970 \mathrm{~s}$, while relatively younger informants felt the decline began in the mid-1980s.

More than $85 \%$ of the informants $(n=58)$ felt that the timing of the snowfall had undergone a change. For them, the onset of early snow in December and January had occurred more infrequently over time and the

${ }^{2}$ People have a finely tuned perception of the amount of snowfall that takes into consideration the topographic variations within the valley. When talking about decreasing snowfall, for example, they will compare amounts of snowfall at several places to indicate a pattern. In the Kullu Valley, the permanent snowline is visible around the year and is not considered by people to directly influence the microclimate of an area period of snowfall now extended through the months of February and March. Informants suggested that early snow was more long lasting and resistant to melting than was the late snow. Besides contributing nitrogen for plant use, early snow was additionally suggested to replenish soil moisture and prevent the buildup of humidity in late March and early April. ${ }^{2}$

\subsection{Rainfall}

Participants in the study reported no discernible change in the intensity of rainfall. There was a shift reported in the distribution of rain across time. Locals said the monsoon rains were slightly displaced to the period beyond mid-August. Local perceptions further indicated that the incidence of rainfall in March and April has increased, coinciding with a significant increase in the number of cloudy days during that period. These changes were seen as a consequence of increasing amounts of late snowfall.

\subsection{Temperature}

There is a perception that the temperature distribution has undergone a significant shift in addition to an overall increase in temperatures. For example, the hottest period of the year is no longer the month of Jeth (15 May to 15 June), but has shifted ahead. The months of March and early April, on the other hand, are colder than usual. The periodicity of temperature is believed to be influenced by the timing of snowfall. Late snowfall, for example, was implicated as a causal factor leading to cooler temperatures in March and April. 


\subsection{Extreme weather phenomena}

The increase in phenomena such as cloudbursts was widely noted. Incidence of landslides, on other hand, was perceived to have slightly declined or remained relatively constant over time. Elderly people recalled 2 major floods in their lifetimes, the first in 1947 and the latest in 1995. The floods were recalled in terms of human life and property. The earlier flood was, interestingly, always recalled in association with religious riots that occurred in the same year. Divine intervention to wash away bloodshed in the valley was given as an explanation of the phenomena.

\section{HYPOTHESES AND DISCUSSION}

Apple farmers use snowfall and rainfall incidences to describe deviations from normal or 'ideal' climate. Moreover, distinctions are also made regarding the timing and distribution of various aspects of the weather cycle. These perceptions are informed by the habitus of the apple farmers of the Kullu Valley, which as a 'system of enduring and transposable dispositions, functions as the generative basis of structured, objectively unified practices' (Bourdieu 1977, p. 82). Bourdieu's concepts of habitus and field and their dialectical interplay is particularly trenchant as they provide a fruitful way of overcoming the objective/subjective duality that often plagues accounts of human-environment interaction. Thus, the perceptions of climatic variables, while ultimately being constrained by the finite range of their values, are more proximately structured by the intersection of the personal, objectified histories as embodied in the habitus of social actors and the field of agriculture as a repository of differential practices and strategies. For instance, perception of rainfall rather than being the imprint of 'objective' environmental conditions, or conversely, the manifestation of an a priori mental template, is the result of the interplay of agriculture as an economic and cultural activity and the 'position' of the hill farmer.

The perception of climate change is informed and structured by the dynamic nature of human-environment relationship in the Kullu Valley. The traditional weather calendar, for example, provides a template or a set of predispositions that constitute the habitus and makes possible the comprehension and interpretation of changed climatic conditions due to 'analogic transfer of schemes permitting the solution of similarly shaped problems, and thanks to the unceasing correction of the solutions obtained' (Bourdieu 1977, p. 83).

Farmers made sense of local climate through the use of categories that were not limited to or determined by the traditional weather cycle. On what basis, therefore, do farmers perceive climatic change? Why are farmers' perceptions of particular changes in weather cycle so widely shared? Two possibilities arise from these questions:

(1) The phenomena farmers perceive are intrinsically noticeable. For instance, visual salience ${ }^{3}$ of snowfall might make it more easily observable than changes in temperature extremes during summer. Thus, people are more likely to notice, especially over time, types of change that are visually more salient.

(2) The phenomena farmers perceive are associated with particularly important outcomes. Apple farmers, for example, are most likely to notice climatic events associated with changes in their apple crop. Therefore, farmers reduce and order vast amounts of potential climatic information through the knowledge of relatively well-defined 'windows' of apple performance-related parameters. For example, apple color climatically depends on the amount of sunshine in the month of August. Therefore, if a month was marked by more than 'usual' cloudiness and apples do not develop a bright red color, the deviation of cloud cover from its ideal pattern will be noted by the majority of farmers.

Apple farmers in the Kullu Valley conceptualize weather cycles in a very systematic manner. Actual weather was described by its deviance from the ideal weather cycle. Exceptional decreases in snow, for example, were discussed in a comparison with other years. People often pointed out that, 'the snowfall used to be as high as two and one-half to three feet here, whereas now it is hardly an inch'. Local perception of changes in snowfall is therefore predominantly in terms of the deviation (e.g. decrease) from, perhaps, the more visually salient maximum annual precipitation; in other words, perceptions are not centered at average values. Therefore, it could very well be that the average snowfall over a particular $5 \mathrm{yr}$ period might be perceived as having increased because maximum snowfall had increased, while average precipitation may have decreased or been static. Also, there is relatively little mention of the absolute amount of snowfall. Since perceptions of snowfall are widely shared in the village, amounts that are registered as 'normal' are nonarbitrary. The specific patterns of variation between individuals should be the subject of later studies, but this is not to say that perception is nonutilitarian. Fig. 1 indicates that periodic (decadal) maximum snowfall has indeed decreased. Local perceptions of precipitation changes seem to be conditioned by these declining amounts.

\footnotetext{
${ }^{3}$ Visual salience' is used to refer to the intrinsic property of the phenomenon, which renders it more observable due to the existence of a corresponding psychophysical or physiological processing mechanism
} 


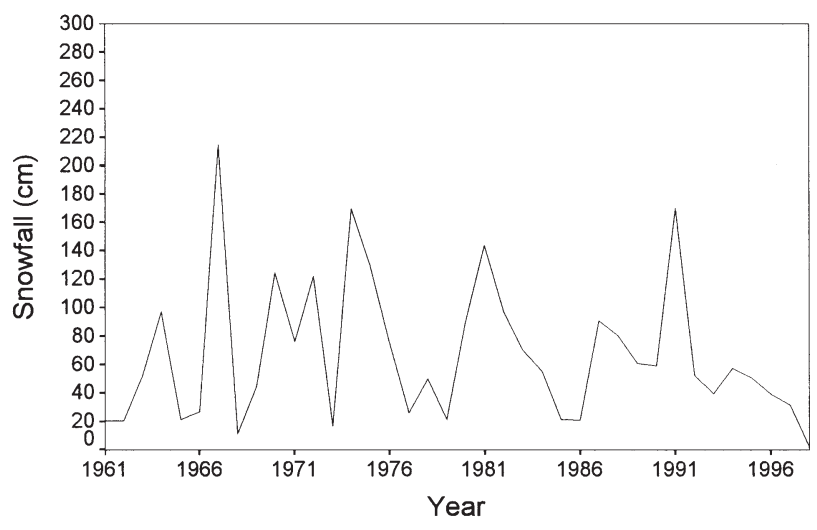

Fig. 1. Annual snowfall in the Kullu Valley, 1961-1996

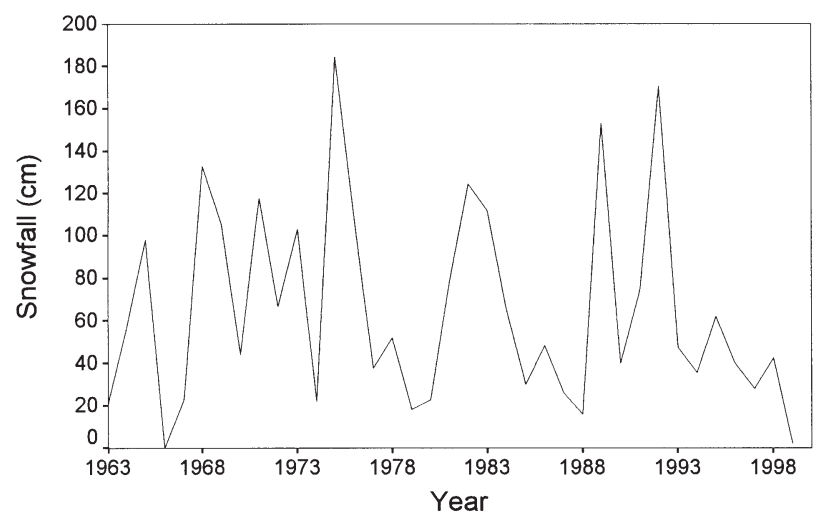

Fig. 2. Early snowfall in the Kullu Valley, December to February 1961-1996

As previously noted, perception of the intensity/ maximum of snowfall is closely linked to the perception of snowfall distribution. In fact, the perception of a changed climatic pattern on the whole seems to be derived from the perception of a reduced intensity of snowfall. That a temporal distribution of snowfall can be derived from the higher intensity of snowfall means a greater proportion of snowfall will occur early in the year (see Fig. 2). According to farmers, late snowfall in February and March occurs mostly as a mixture of sleet and rain, resulting in lower temperatures and thereby a late onset of spring (see Fig. 3).

The local perception of climate seems patterned by its utilitarian aspects. It is interesting to note that the patterns of change described by farmers are closely linked to the annual growth cycle of apples. Amount of snow determines the number of chilling hours and thereby the time of bud-break. If snow has been normal-heavy, approximately 2 to $3 \mathrm{ft}(60$ to $90 \mathrm{~cm})$, the perception of its occurrence is positively correlated with heavy early snow and little late snow. Therefore, a snow level of 2.5 to $3 \mathrm{ft}$ seems to represent the opti-

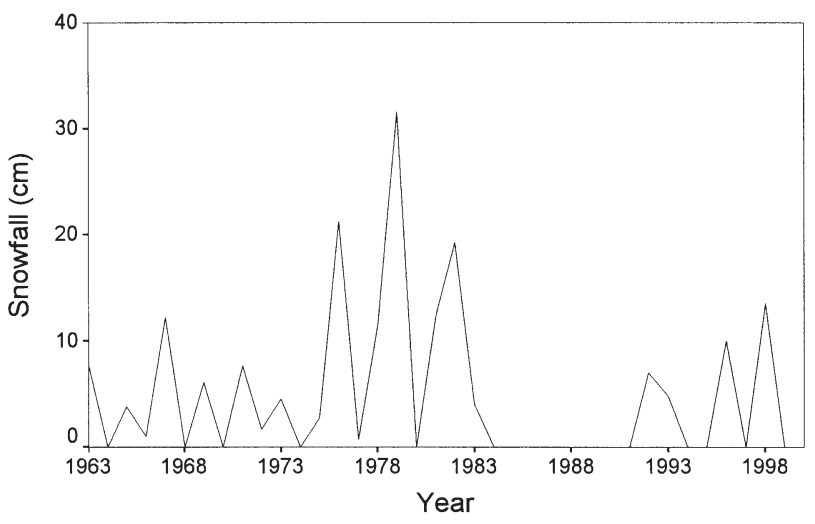

Fig. 3. Late snowfall in the Kullu Valley, March to April 1961-1996

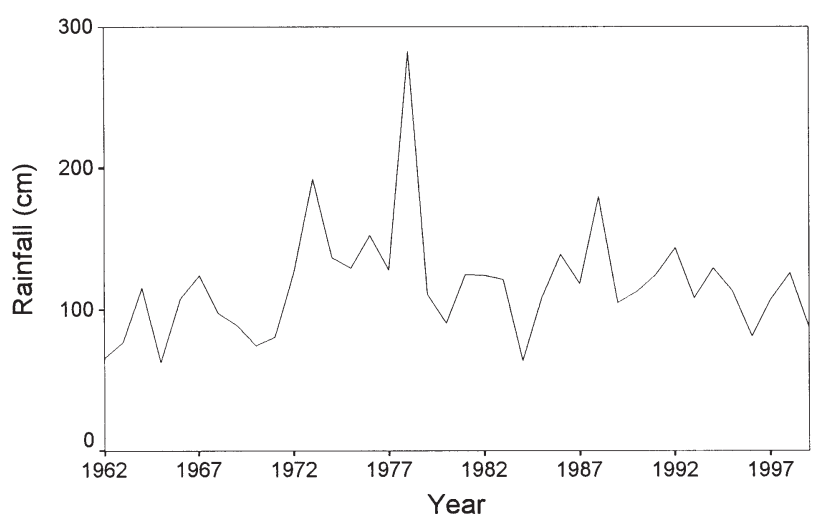

Fig. 4. Annual rainfall in the Kullu Valley, 1962-1999

mal pollination and fruit-bearing conditions for an apple crop. Early snow is regarded as durable, longlasting and full of nitrogen; late snow, on the other hand, is described as watery, transitory and understood to adversely impact pollination and apple fruitbearing. Both the amount and the distribution of snowfall are utilized as local benchmarks for assessing the utilitarian effect of snowfall. Particularly significant is that the high correlation between early snowfall (December-January) and total/annual snowfall intervals for the $37 \mathrm{yr}$ concerned, with a Pearson's R of 0.769 at $99 \%$ confidence. Almost inevitably, any mention of early or late snow is accompanied by a description of its impact on the yield or performance of apple.

There was a trend over the 37 yr towards decreased amounts of annual rainfall (Fig. 4), but rainfall was predominantly perceived in terms of its temporal distribution-the attribute on which the color of an apple mostly depends and, more importantly, the survival of the plant itself depends by its regulation of moisture stress. In addition, actual fluctuations in the amount of annual rainfall were not very significant compared to 
the actual amount of annual snowfall. On the other hand, snowfall has fluctuated wider in its amount as well as its distribution.

Similarly, very little change in weather was perceived beyond the month of September, after the apple harvest (see Table 3). It is plausible that people conceptually lump increased rainfall with extreme weather phenomenon such as perceived increases in cloudbursts. One can further speculate on the relationship between this categorization and the clearly awesome and destructive nature of these events. Considering that weather cycles were described overall as displacement, it would be difficult to accommodate these extreme events in their framework without marking the events as the modal, or as religiously significant. The marking of extreme rainfall events as 'floods' helps tie weather to events of religious significance (in addition to their obvious utilitarian impact) and therefore make them highly memorable. For example, most informants agreed on the number and timing of major floods that had hit the valley since their first recollections of 1947 .

The perception of altered temperature distribution can be regarded as a derivative phenomenon. Overall, of course the climate is described as being much warmer. But people's perceptions of temperature changes are not simply described as increases or decreases; they are mainly related to changed distributions. Temperature aspects of the weather cycle have been particularly displaced; e.g. cold weather lasts well into April and May. The month of July witnesses very hot temperatures instead of the ideal 'rainy, warm and humid' patterns, and the changes are viewed as a result of temporal changes in snowfall.

Thus, the overall description of displaced climate change implicitly includes comparisons with the normal/traditional weather calendar. People filter or aggregate their descriptions of activities that overlap 2 mo of the traditional calendar; this makes possible a timing of activities that could not be accommodated by a strict adherence to an 'ideal' month. The traditional weather calendar, therefore, is a model for rather than of climate and acts as a template for the conceptual organization of climate-dependent activities in a temporal fashion. In spite of this purpose, the given weather cycle does not determine or constrain the perception of climate as anomalous.

\section{KNOWLEDGE OF APPLE-CLIMATE INTERACTIONS}

The perception of climate change is shaped mainly by the associated impact of changed climatic conditions on the apple crop. The knowledge of apple-cli- mate interaction, therefore, mediates local perception of climatic change. The main patterns of crop-climate interaction that underlie apple farmers' perception of climate change concern the impact of changed climatic conditions on (1) blossoming and yield, (2) fruit quality, and (3) ecological ramifications.

Firstly, climatic changes alter the pattern of blossoming, bearing and, therefore, fruit yield. The lack of early cold in December and January is understood to adversely affect the chilling requirements, which range from 700 to $1200 \mathrm{~h} \mathrm{yr}^{-1}$. As Abbott (1984) points out, a chilling requirement averaging $10 \mathrm{wk}$ below $5^{\circ} \mathrm{C}$ is required to meet the internal conditions necessary for bud-break with the onset of spring temperatures. An April late cold can delay blossoming and reduce the pollination activity of bees. Also if it rains in this period, there is a risk that pollen will be washed away from plants. The amount of snow is understood to strongly influence soil moisture, especially in the case of early snow. Late snow, besides having a negative impact in several other aspects, also fails to replenish soil moisture to the desired degree. In addition, late snow affects the process of pollination indirectly; a relative immobilization of bees is triggered due to low temperatures brought about by late snowfall. ${ }^{4}$

Secondly, climate changes affect apple quality. Moreover, the degradation of quality is not uniform throughout the valley; there are distinct patterns. People often remarked that the apple belt is moving up in the valley. In Bajaura, located in the lower part of the valley, goodquality apples that fetched competitive prices were produced 10 to $15 \mathrm{yr}$ ago. Due to a gradual reduction in quality, many apple orchards are no longer viable, accounting at least partly for their transition to vegetables. There was a broad consensus that the lower limit of apple cultivation has extended to Raisan, approximately $30 \mathrm{~km}$ north of Bajaura in the valley.

Lastly, there are ecological ramifications of changes in climatic conditions. There is a widely held perception that the increasing incidence of pest and disease comprises a shift in disease ecology and that climate change has played a vital role. Canker, a disease that causes a tree to decay, has become more rampant. The rate of infection is now between 5 and $10 \%$, and an increasing number of sprays are now required for the routine control of pests. The number of sprays has increased from about $4 \mathrm{yr}^{-1}$ in the $1970 \mathrm{~s}$ to about $12 \mathrm{yr}^{-1}$ today.

The categories through which the environment is perceived and acted upon can, therefore, be regarded

\footnotetext{
${ }^{4}$ Himalayan honeybee Apis cerana, endemic to the area, starts foraging at temperatures as low as $7^{\circ} \mathrm{C}$, whereas Apis mellifera, which has been introduced over the last $10 \mathrm{yr}$, begins at around $13^{\circ} \mathrm{C}$ (Pratap \& Pratap 1997)
} 
as prescriptive (Shweder 1991). Furthermore, categories are inductive but local characterization of weather cycle as 'disturbed' seems to be ordered by the intention of the social actors. It should be noted that an emphasis on practical intentionality does not rule out the visual salience or biologically pre-potency of changes (Shweder 1991). The basis for meaningful action lies in the structure of perception, or the relationship people observe between different parts of the weather cycle. This structure cannot be explained without consideration of a socio-cultural context that includes an implication for the intentional nature of these categories. ${ }^{5}$ Humans register climatic phenomena by their intrinsic salience, but this salience neither defines nor determines the structure of perception. In the case at hand, for example, both the perception of climate change and its structure depend on the perception of their associated impact on apple production. The relationship between perception and climate seems to be governed by what Ingold (1992) described as the dialectical relationship between 'affordances' of the environment and the 'effectivities' of the social actors. Thus, perception of climate change is structured on one hand by apple farmers' activities in terms of the knowledge and intentions they possess, and on the other by parts of the landscape (i.e., 'affordances') that, even though pre-existing, make sense only in light of the activities (in this case, apple growing) ${ }^{6}$ The requirement of Red Delicious variety for a specific and interrelated complex of environmental conditions $\left({ }^{\prime} n i c h{ }^{17}\right)$ renders its performance highly variable over time and space. In addition the existence of niches as discontinuous and fragile patches also imparts an easy observability, which needless to say is not deducible from the environmental conditions alone in vacuo but can properly be understood only in light of the whole

${ }^{5}$ Paul Sillitoe's (1996) study of the ethnoclimatology of Wola, Papua New Guinea, demonstrates that even in a region with what can only be described as an undifferentiated weather regime, 2 distinct seasons are perceived that correspond closely with the meteorological data. The perception of climate is structured by the distinct agro-ecological outcomes associated with different aspects of the 2 seasons

${ }^{6}$ Ingold's (1992) conceptualization of perception of environment as deriving from the immersion in an active relationship is treated as a special case of Bourdieu's much more inclusive concepts of habitus and field. Thus, the humanenvironment interaction can be best studied not by consideration of disembodied, abstract and a priori models and categories but by recovering it from the web of concrete practices which are historical and context bound

${ }^{7}$ The environmental niche of apple can be considered to be structured along the following dimensions: (1) elevations between 1200 and $1500 \mathrm{~m}$ that provide the requisite chilling hours and low risk of frost and hailstorms and (2) the interaction of aspect and soil moisture that can control moisture stress of human-environment relationship. It is highly probable that, historically, the local cultivars of maize and rice occupied the same position.

\section{CONCLUSION}

Three main implications follow from this analysis. Firstly, the cultural model of climate as it is evident from the weather calendar fails to anticipate the perception of climate change. Even though the concepts of cycle and displacement seem to be borrowed from the traditional weather cycle, they basically act as no more than templates for the organization of the perception of climate change. A more productive way of explaining these perceptions can be based on the concepts of habitus and field as used by Bourdieu (Calhoun 1993). Here, environmental perception and action would not be conceived entirely on the basis of precursor-like role of cultural models constituted by attitudes (Kempton et al. 1995, Strauss \& Quinn 1997). The former approach will allow for the consideration of cultural models as being construed 'for' rather than 'of' climate, implying therefore that the constituting knowledge can be strategically deployed; in other words, it does not encompass the 'whole' of the human-environment interaction in the present context. ${ }^{8}$

Secondly, policy based solely on educating people (changing their models 'of' climate) as a means of generating consensus on the issue of global warming and its potential solution is not likely to go very far. A pragmatic approach in this regard must also include (dis)incentives for adherence to recommendations aimed at mitigating specific problems.

Thirdly, the story of climate change perceptions as told here is only half-complete because it does not provide any understanding of the way(s) in which these perceptions can be the basis for action. This part involves the embedding of these perceptions in regional discourses of farmer's rights. In other words, understanding their relevance for action requires an understanding of how perceptions are imparted with political-economic valence (translated into politicaleconomic agendas). The process involves 'continuous

\footnotetext{
${ }^{8 `}$ Models for' refers to the understanding of an environment animated as a result of the process of active engagement; in contrast, 'models of' comprises detached and passive knowledge. We have somewhat modified Ingold's (1992) dichotomization of environmental knowledge as engaged and passive by placing these at the ends of a continuum which restores importance to representations, ideologies, etc., albeit in a secondary role. The position has implications for research as it concedes primacy to the empirical examination of environmental practice over dissection of representations as a means to understanding perception and action
} 
interaction between (en)textualization and (con)textualization' (Silverstein \& Urban 1996, p. 4), and as a result 'sectarian' perceptions come to acquire social salience.

Climate variability and changes have rendered the role of planning and research in agricultural more crucial than ever before, and the climate factor thus needs to be included in any program aimed at maintaining and enhancing the agricultural sustainability of the northwestern Himalayan region (Ives et al. 1997). In order to understand how humans would respond to climate change, it is essential to study people's perceptions of climate and the environment in general. Since it forms the basis of decision-making, local knowledge of climate should be incorporated into any strategy meant to mitigate the impact of climate change. Any framework for understanding decision-making must be based on criteria more inclusive than just economic maximization. The understanding of the costs and benefits associated with a particular course of action is shaped by the materials offered within the objective world of the agent since 'what one thinks' is related to 'how one thinks' and the relationship between the two is mediated by the worldview to which one adheres (Shweder 1991, p. 155). The framework for making agricultural decisions and climate cannot thus be isolated from culturally constituted ways of seeing, knowing and valuing the world.

Acknowledgements. The authors wish to thank Eric Jones and Mika Cohen for their editorial corrections and insights. They are grateful for the critical comments of an anonymous reviewer.

\section{LITERATURE CITED}

Abbott DL (1984) The apple tree: physiology and management. Grower Books, London

Apple Growers Association (1997) Production data sheets. Apple Growers Association, Kullu Valley, Himachal Pradesh

Bourdieu P (1977) Outline of a theory of practice. Cambridge University Press, New York

Calhoun C (1993) Habitus, field and capital: the question of historical specificity. In: Calhoun C, Lipuma E, Postone M (eds) Bourdieu: critical perspectives. The University of Chicago Press, Chicago, p 45-61

Chmielewski F (1992) Impact of climate changes on crop yields of winter rye in Halle (southeastern Germany), 1901-1980. Clim Res 2:23-33

Submitted: January 19, 2000; Accepted: February 13, 2001
Crumley CL, Marquardt WH (1987) Regional dynamics: Burgundian landscapes in historical perspective. Academic Press, San Diego

Directorate of Horticulture (1998) Horticulture development: facts and figures. Directorate of Horticulture, Shimla

Glantz MH (ed) (1994) Drought follows the plow: cultivating marginal areas. Cambridge University Press, New York

Glantz MH (ed) (1998) Societal response to regional climatic change: forecasting by analogy. Westview Press, Boulder, $\mathrm{CO}$

Gunn JD (1994) Global climate and regional biocultural diversity. In: Crumley CL (ed) Historical ecology. School of American Research Press, Santa Fe, NM, p 67-99

Ingold $\mathrm{T}$ (1992) Culture and perception of the environment. In: Croll E, Parkin D (eds) Bush base: forest farm, culture, environment and development. Routledge, London, p 39-56

Ives JD, Bruno M, Rhoades RE (1997) Agenda for sustainable mountain development. In: Messerti B, Ives JD (eds) Mountains of the world. The Parthenon Publishing Company, New York, p 409-445

Kempton W, Boster JS, Hartley JA (1995) Environmental values in American culture. MIT Press, Boston

Lamb MM (1985) Climatic history and the future. Princeton University Press, Princeton, NJ

Orlove B, Chiang JCH, Cane MA (2000) Forecasting Andean rainfall and crop yield from the influence of El Niño on Pleiades visibility. Nature 403:68-71

Parry ML (1978) Climate change, agriculture and settlement. Archon Books, Hamden, CT

Parry ML, Carter TR, Konijin NT (eds) (1989) The impact of climatic variations on agriculture, Vol 1. Assessments in cool temperate and cold regions. Kluwer Academic Publishers, Dordrecht

Post JD (1985) Food shortage, climatic variability, and epidemic disease in pre-industrial Europe. Cornell University Press, Ithaca

Pratap U, Pratap T (1997) Managed crop pollination: the missing dimension of mountain agricultural productivity. Discussion paper series no. MFS 97/1. International Centre for Integrated Mountain Development, Kathmandu

Scott MJ, Rosenberg NJ, Edmonds JA, Cushman RM and 7 others (1990) Consequences of climate change for human environment. Clim Res 1:63-79

Sharma AN (1997) Growth, employment and poverty: change and continuity in rural India. Vikas Publications, New Delhi

Shweder R (1991) Thinking through cultures: expeditions in cultural psychology. Harvard University Press, Cambridge, MA

Sillitoe P (1996) A place against time: land and environment in the Papua New Guinea highlands. Harwood Academic Publishers, Amsterdam

Silverstein M, Urban G (1996) Natural histories of discourse. University of Chicago Press, Chicago

Strauss C, Quinn N (1997) A cognitive theory of cultural meaning. American Anthropological Association, Arlington, VA

Proofs received from author(s): October 5, 2001 